\title{
Association between trigeminal neuralgia and multiple sclerosis: role of magnetic resonance imaging
}

\author{
J F M Meaney, J W G Watt, P R Eldridge, G H Whitehouse, J C D Wells, J B Miles
}

\begin{abstract}
Seven consecutive patients with multiple sclerosis and trigeminal neuralgia were investigated with MRI to determine the occurrence of a lesion which would account for the patients' pain. Two patients had bilateral symptoms. In the patients with unilateral trigeminal neuralgia vascular compression of the nerve by an artery at the root entry zone on the symptomatic side was confirmed in three patients and an epidermoid tumour distorting the nerve on the symptomatic side was identified in one patient. A demyelinating plaque was identified in only one patient, affecting the trigeminal nerve at the root entry zone at the pons. In those with bilateral symptoms neurovascular compression was identified on both sides in one patient and on one side only in the remaining patient. Microvascular decompression cured the pain in two patients with neurovascular compression. The variable aetiology of trigeminal neuralgia is stressed even in patients with coexistent neurological conditions such as multiple sclerosis, which can cause trigeminal neuralgia independent of other causes.
\end{abstract}

$(\mathcal{F}$ Neurol Neurosurg Psychiatry 1995;59:253-259)

Keywords: trigeminal neuralgia; magnetic resonance imaging; multiple sclerosis

University

Department of

Radiodiagnosis, 2nd

floor Johnston

Building, University

of Liverpool, L69 3BX,

UK

JF M Meaney

G H Whitehouse

Pain Research

Institute, Rice Lane,

Liverpool, L9 1AE

JW G Watt

J C D Wells

Walton Centre for

Neurology and

Neurosurgery, Rice

Lane, Liverpool,

L9 1AE, UK

$P$ R Eldridge

J B Miles

Correspondence to:

Mr J B Miles.

Received 8 June 1994

and in final revised form

16 March 1995

Accepted 20 April 1995
The aetiology of trigeminal neuralgia is multifactorial, but it is becoming increasingly recognised that most so called "idiopathic" cases are due to vascular compression of the nerve by a looping blood vessel where the nerve enters the pons. ${ }^{1-4}$ About $1-2 \%$ are caused by demyelinating plaques of multiple sclerosis affecting the trigeminal pathway and the results of many postmortem examinations support this notion..$^{5-8}$ About $10 \%$ of cases are due to cerebellopontine masses compressing or invading the nerve. ${ }^{9}$

We emphasise that trigeminal neuralgia in patients with multiple sclerosis must not be attributed solely to demyelination, without exclusion of other causes such as vascular compression or tumours.

\section{Patients and methods}

Seven consecutive patients with both multiple sclerosis and trigeminal neuralgia were inves- tigated by MRI. Two patients had bilateral trigeminal neuralgia. All images were obtained on a Siemens Magnetom 1.5 Tesla MR scanner. All patients had a sagittal T1 weighted localiser (TR/TE 500/15 ms). Conventional T2 weighted and proton density weighted images (TR/TE 2,000/80/20 ms) or fast spin echo T2 weighted images (TR/TE $3800 / 93 \mathrm{~ms}$ ) were obtained in four patients. Magnetic resonance tomoangiograms (MRTAs) of the intracranial vasculature were obtained by a three dimensional fast inflow with steady state precession sequence, which is routinely employed for depiction of the intracranial vasculature at our institution. Images were acquired axially over the pons. Scanning parameters were TR 29-36 ms, TE $7 \mathrm{~ms}$, flip angle $15^{\circ}, 64$ partitions, $55 \mathrm{~mm}$ slab, $22 \mathrm{~cm}$ field of view. This technique yielded 64 slices each of $0.9 \mathrm{~mm}$ thick. Operator defined reconstructions centred around the trigeminal nerves were performed to determine the presence or absence of vascular compression. So as not to confuse this technique with $\mathrm{MR}$ angiography, which provides information about the vessels only, the term magnetic resonance tomoangiography has been used. ${ }^{10}$

\section{Case reports}

PATIENT 1

A 40 year old woman presented with a one year history of second division trigeminal neuralgia on the right side. She had had a series of attacks 19 years earlier, which had responded to carbamazepine. Five years previously an episode of optic neuritis led to a diagnosis of multiple sclerosis. A conventional MRI showed several areas of increased signal consistent with multiple sclerosis.

Carbamazepine (600 mg daily) initially controlled the pain but one year after the onset of symptoms she was taking $1400 \mathrm{mg}$ carbamazepine and $0.5 \mathrm{mg}$ clonazepam daily. A glycerol trigeminal ganglion block gave only limited relief, and so a trial of dorsal column stimulation was performed. High cervical stimulation gave complete pain relief for three hours after stimulation was stopped. Permanent dorsal column stimulation was planned.

An MRTA clearly showed compression of the right trigeminal nerve at the root entry zone by the superior cerebellar artery (fig 1A, B) This finding prompted microvascular decompression of her right trigeminal nerve (rather than implantation of a permanent dor- 

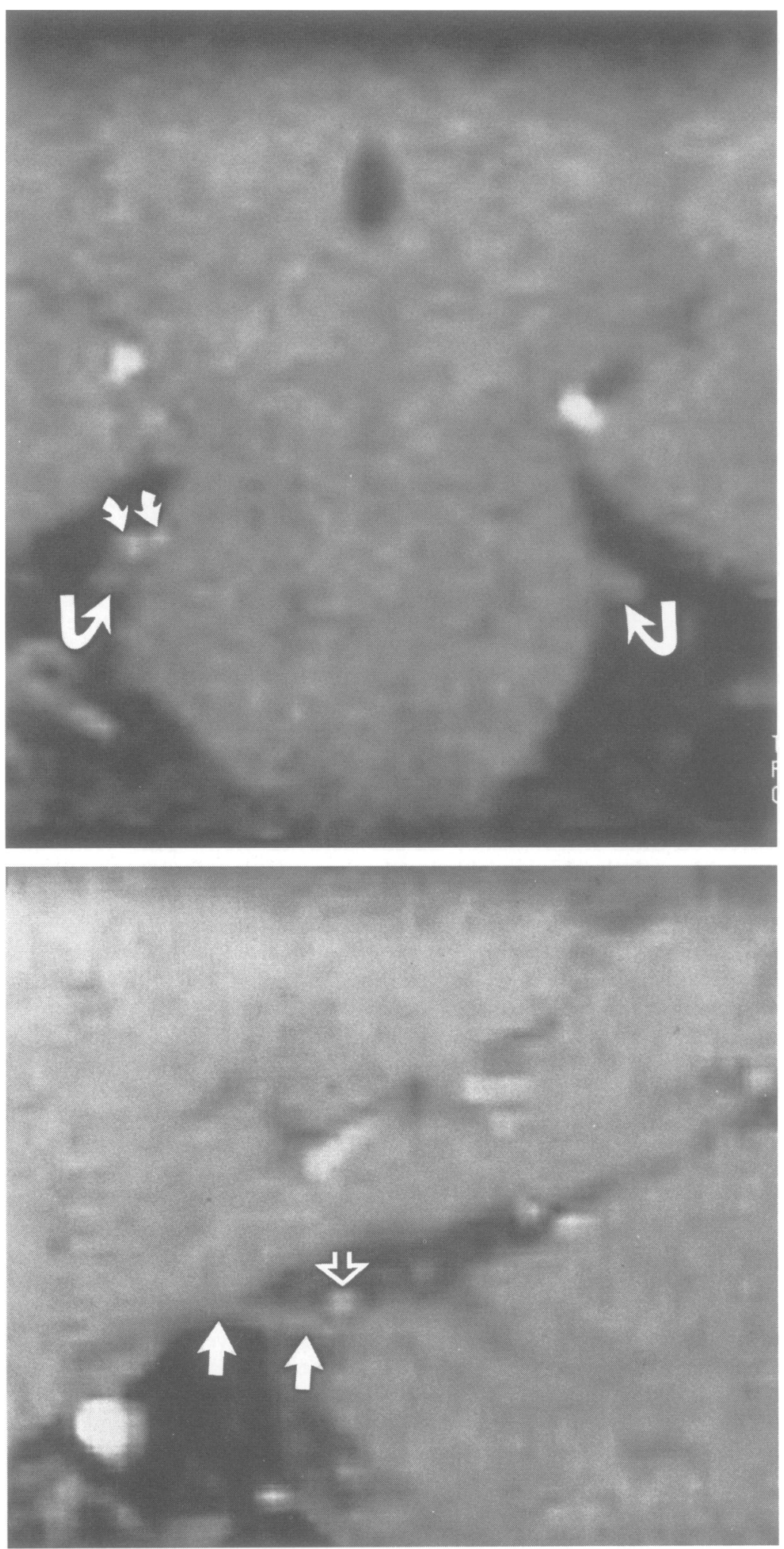

Figure 1 (patient 1): (A) Coronal MRTA of pons. Both trigeminal nerves are indicated (arge curved arrows). Note compression of the right trigeminal nerve by a caudally looping superior cerebellar artery (small curved arrows). No evidence of compression on the left side. (B) Sagittal MRTA along the right trigeminal nerve (solid arrows) showing compression of the nerve superiorly at the root entry zone by the superior cerebellar artery (open arrow) fested as optic atrophy and ataxic spastic quadriparesis for 12 years. Carbamazepine was effective in relieving trigeminal neuralgia but exacerbated her multiple sclerosis symptoms to such a degree that she became confined to a wheelchair on high doses. She took $800 \mathrm{mg}$ carbamazepine daily increasing to $1600 \mathrm{mg}$ during exacerbations. A posterior fossa trigeminal nerve rhizotomy had previously been planned but was cancelled due to the severity of her multiple sclerosis. A radiofrequency lesion of the second division gave three months of complete relief, and partial relief for a further six months. She is currently well controlled on $800 \mathrm{mg}$ of carbamazepine daily.

An MRTA showed no evidence of vascular contact with the nerve. Conventional T2W and proton density MRI showed multiple areas of increased signal intensity consistent with multiple sclerosis, and a large discrete plaque affecting the pons at the level of the trigeminal nerve on the symptomatic side (fig 2).

\section{PATIENT 3}

After 25 years of multiple sclerosis, a 54 year old man had no movement below the neck and a bulbar palsy. He had left third division trigeminal neuralgia for six years and was taking $800 \mathrm{mg}$ of carbamazepine daily, which gave only limited pain relief.

An MRTA disclosed a single artery compressing and displacing his left trigeminal nerve at the root entry zone. Unfortunately his condition was so severe that surgery was not offered. Radiofrequency nerve destruction was not performed because of his inability to communicate, which would have made it impossible for the operator to assess the needle position during sensory testing. Reasonable pain relief was achieved by injection of absolute alcohol into the trigeminal ganglion.

\section{PATIENT 4}

A 60 year old woman had multiple sclerosis for 20 years and was wheelchair bound due to lower limb weakness. Two years previously she had developed severe shooting pains in the second division of her left trigeminal nerve. Initially attacks lasted 20 minutes but at presentation they were almost constant. Carbamazepine relieved her pain but caused a florid skin rash. Phenytoin was ineffective and caused hallucinations. Sodium valproate gave only limited relief and at a high dose exacerbated her ataxia and induced tremor.

An MRTA showed no evidence of vascular compression but the nerve was medially deviated by a well circumscribed mass (fig $3 \mathrm{~A}$ ), and T2W MRI (fig 3B) showed a mass lesion extending along the left petrous ridge, distorting the left trigeminal nerve. Changes consisting of extensive demyelination with several small demyelinating areas in the midbrain and pons were also noted. She is currently awaiting surgery for her tumour. 


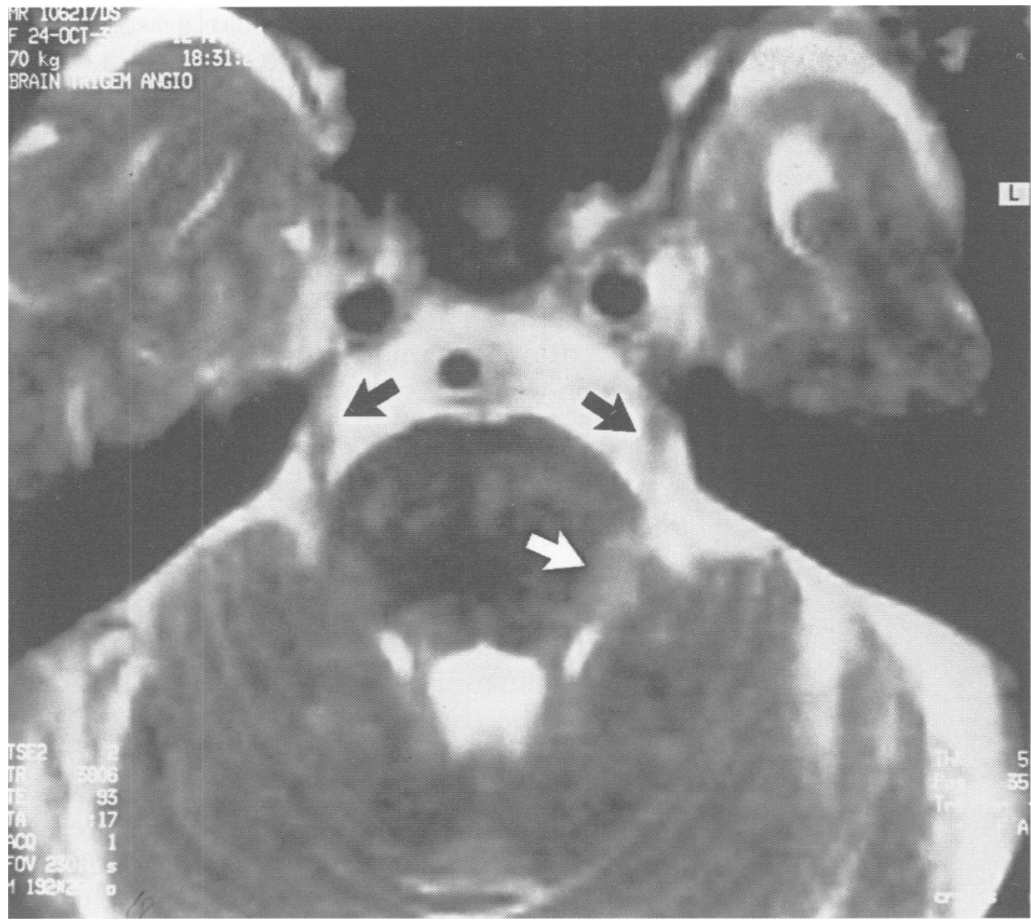

Figure 2 (patient 2): T2 weighted magnified image at the level of the pons. Both trigeminal nerves are visible as low signal intensity structures (black arrows) suspended within the high signal CSF. Note high signal intensity plaque (white arrow) extending posteriorly from the left trigeminal nerve root entry zone.

\section{PATIENT 5}

A 64 year old man had bilateral leg and left arm weakness after 36 years of multiple sclerosis. Fourteen years ago he developed left second division trigeminal neuralgia which was effectively treated by a radiofrequency nerve lesion. Three years later he developed neuralgia in his left first division, which also responded to a radiofrequency lesion that left him with left sided facial anaesthesia.

Eight years ago he developed right second division trigeminal neuralgia. To limit the extent of nerve destruction, the infraorbital nerve was exposed and frozen with a cryoprobe. This gave only six months of relief. Over the next six years he underwent four radiofrequency lesions of the right trigeminal nerve. Although the first lesion gave two years of relief, subsequent lesions had a shorter duration of action until the final lesion had no effect. He was now anaesthetic in all three divisions of the left trigeminal nerve, anaesthetic in the second division, and hypoaesthetic in the first division of the right trigeminal nerve. Carbamazepine $(600 \mathrm{mg}$ daily) gave only limited relief but worsened his multiple sclerosis symptoms such that he could no longer feed himself and his speech became incomprehensible.

An MRTA showed vascular compression and distortion of the right trigeminal nerve between the superior cerebellar artery above and a further small artery below (fig 4A, B). Vascular compression on the left side by a single vessel was also noted.

The pain of his trigeminal neuralgia was now intolerable, carbamazepine was not tolerated, and radiofrequency lesions were ineffective. Despite the severity of his multiple sclerosis the patient and his family considered that the risks of surgery were justified. After successful microvascular decompression of the right trigeminal nerve he was completely free of pain. Unfortunately, he subsequently developed a chest infection from which he died five days later.

At postmortem, multiple, sclerotic, translucent plaques were seen throughout the white matter of the cerebral hemispheres, the cerebellum, pons, medulla, and spinal cord. Serial sections through the pons showed typical demyelinating plaques in the root entry zones of both trigeminal nerves, most pronounced on the right side. On the left there was also considerable axonal loss with secondary demyelination along the whole length of the trigeminal nerve tract, assumed to be due to radiofrequency thermocoagulation of preganglionic nerves 10 years earlier.

\section{PATIENT 6}

A 44 year old woman had multiple sclerosis for 25 years, manifested as optic neuritis on several occasions and persistent spastic paraparesis of the lower limbs. Three years ago, she had been referred by her dentist who had been unable to cure a right sided mandibular pain with tooth extractions. She gave a clear history of third division trigeminal neuralgia and gained good pain relief with carbamazepine ( $1600 \mathrm{mg}$ daily). This dose made her dizzy and sedated, however. Radiofrequency lesioning gave complete relief from pain and numbness in the third division. She was then able to discontinue carbamazepine. Two years later she developed symptoms of trigeminal neuralgia in the mandibular division of her left trigeminal nerve. A combination of carbamazepine (2400 mg daily) with amitriptyline, desipramine, and clonazepam was only partially effective.

An MRTA showed vascular compression of the right trigeminal nerve by an ectatic artery, but no evidence of compression on the left side. The patient was reluctant to undergo surgery. A diagnostic trigeminal ganglion block with $1.5 \mathrm{ml}$ of $1 \%$ lignocaine resulted in 48 hours of total pain relief. As she remained anaesthetic in the third division on the right it was considered that radiofrequency ablation of the left trigeminal nerve carried too great a risk of bilateral sensory and motor dysfunction. Her pain was therefore treated by injecting $0.5 \mathrm{ml}$ of glycerol into the right Meckel's cave which resulted in complete anaesthesia of her face on the symptomatic side. She has been able to stop all medication except carbamazepine at a daily dose of $200 \mathrm{mg}$. Microvascular decompression will be carried out if her symptoms recur.

\section{PATIENT 7}

After 14 years of multiple sclerosis, manifested as spastic paraparesis affecting both lower limbs and the left upper limb, bladder disturbance, and diplopia, this 40 year old woman developed left sided first and second division trigeminal neuralgia six years ago. A 

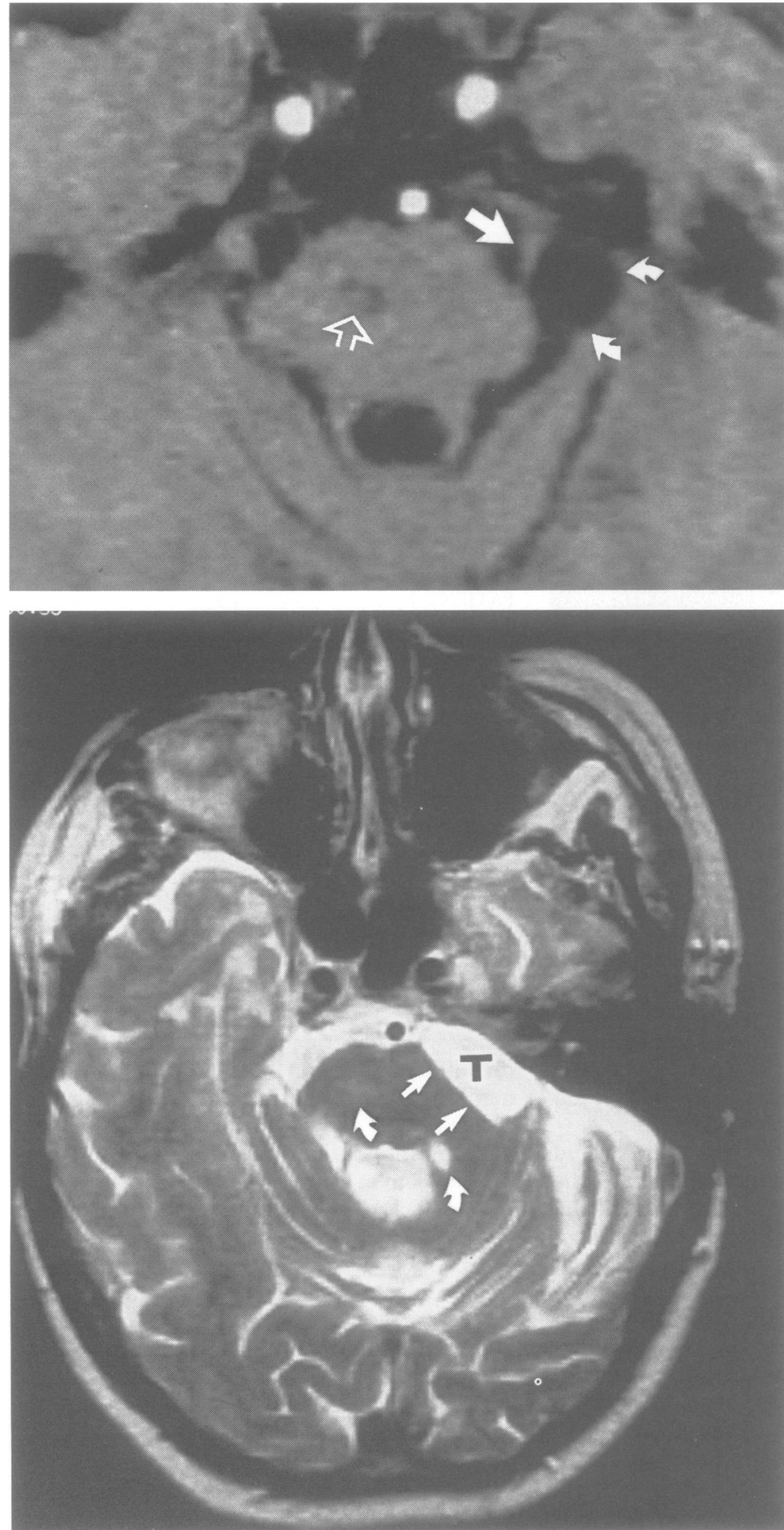

Figure 3 (patient 4): (A) Axial MRTA showing medial deviation of the left trigeminal nerve (straight arrow) by a well circumscribed low signal intensity rounded lesion (curved arrows). Note also low signal intensity area within the pons (open arrow) consistent with a demyelinating plaque. (B) Axial T2W image showing flattening of the left side of the pons (straight white arrows) by a tumour (T) which has a signal intensity slightly higher than CSF. The appearances are consistent with an epidermoid tumour. Note also areas of increased signal intensity (curved arrows) consistent with multiple sclerosis plaques

diagnostic trigeminal block afforded complete pain relief, which lasted for three years. The procedure was successfully employed on two further occasions to treat recurrence. An MRTA on the last occasion showed compression of the left trigeminal nerve at the pons between the superior cerebellar artery above and a small vessel below. At present the pain is fairly well controlled with a combination of ketoprofen and paracetamol. Surgery is not planned unless oral medication and anaesthetic blocks cease to be effective.

\section{Discussion}

Conventional opinion is that trigeminal neuralgia in patients with multiple sclerosis is due to a demyelinating plaque affecting the trigeminal nociceptive pathway..$^{5-811}$ In this small series of nine instances of trigeminal neuralgia (seven patients; two bilateral) associated with multiple sclerosis, a potentially treatable cause was discovered in seven instances. In only one case of unilateral trigeminal neuralgia was demyelination shown to affect the trigeminal nerve root entry zone on the symptomatic side. In four other patients with unilateral trigeminal neuralgia, vascular compression of the nerve was present in three instances, and an epidermoid tumour in one. In two patients with bilateral trigeminal neuralgia, vascular compression was identified on both sides in one patient and on one side only in the other patient. In the patient with bilateral compression radiofrequency coagulation of the trigeminal root had previously effected a cure on one side.

Postmortem examination of the brain has rarely been performed in patients with trigeminal neuralgia and multiple sclerosis. In most cases reported demyelination affected the pons at the root entry zone. ${ }^{6-8}$ Although neurovascular compression of the nerve accounts for most cases of "idiopathic" trigeminal neuralgia, ${ }^{4}$ the neurovascular relations of the trigeminal nerve have not previously been studied in patients with multiple sclerosis and the possibility that vascular compression may be responsible in some instances has been summarily dismissed by most authors. For instance Brisman states that microvascular decompression is contraindicated in patients with multiple sclerosis and trigeminal neuralgia $^{8}$ and even Jannetta and colleagues, ${ }^{212}$ who popularised microvascular decompression, have agreed with this statement. None the less, Lazar and Kirkpatrick reported the demonstration of a plaque affecting the trigeminal nerve at the root entry zone in a patient with multiple sclerosis, in whom a vessel was seen to compress the nerve at operation. ${ }^{13}$ This vessel was dismissed as unimportant, the fact that demyelination was demonstrated histologically being regarded as evidence to refute the relevance of the vessel. We question this assertion, as we are unaware of any firm criteria distinguishing unimportant from important compression as disclosed at operation, and secondly, demyelination is a non-specific response to injury and has been reported in trigeminal nerves at the root entry zone in patients with trigeminal neuralgia who did not have multiple sclerosis. ${ }^{14}$ Furthermore, postmortem examination of the pons disclosed demyelinating plaques bilaterally affecting the root entry zone in patient 5 

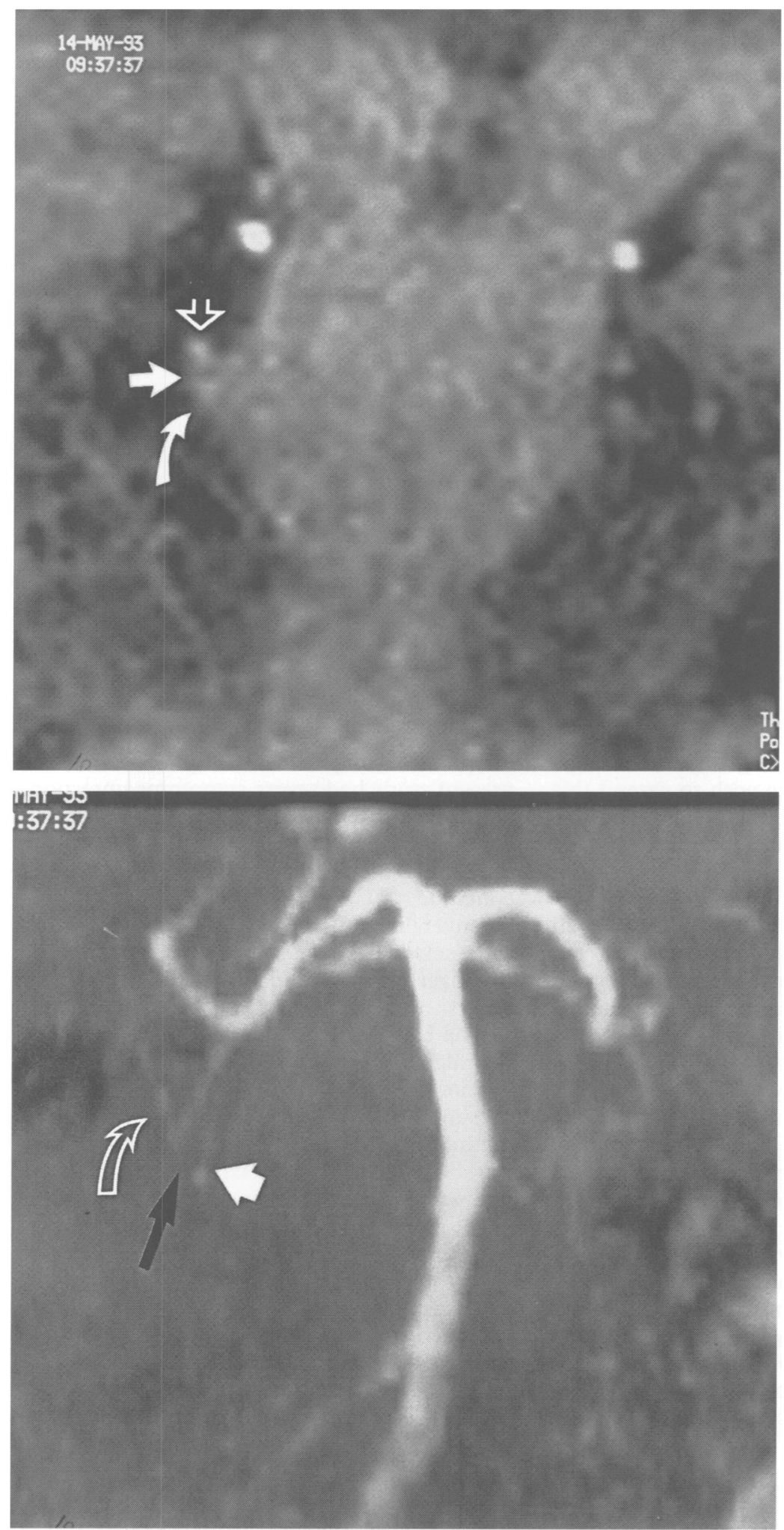

Figure 4 (patient 5): (A) Coronal MRTA showing the right trigeminal nerve (straight arrow), barely visible because of pronounced compression, sandwiched between the superior cerebellar artery above (open arrow), and another vessel below (curved arrow), presumably a branch of the anterior inferior cerebellar artery. (B) Maximum intensity projection angiogram showing caudal looping of the superior cerebellar artery (open curved arrow) and a further small vessel inferiorly (solid white arrow). The site at which the nerve was compressed between these two vessels is indicated (black arrow)

who experienced immediate pain relief after decompression of the right trigeminal nerve, which was sandwiched between two vessels.

The concept of vascular compression of the nerve as a cause of trigeminal neuralgia was first proposed by Dandy, ${ }^{1}$ and the technique of microvascular decompression, in which the vessel is displaced from the nerve at the root entry zone by interposition of a small nonresorbable sponge between the two structures, was popularised by Jannetta. ${ }^{2}$ The notion of neurovascular compression is a widely, but not universally accepted, cause of trigeminal neuralgia. ${ }^{1-4}$ Until recently, demonstration of vascular compression of the nerve was not possible by imaging means. Work at our institute and others has shown that MRTA can confirm or exclude vascular compression of the nerve root and potentially predict which patients will benefit from microvascular decompression..$^{101516}$ In a prospective series of patients with trigeminal neuralgia and age and sex matched controls, vascular compression of the nerve was identified in $85 \%$ of symptomatic cases compared with $8 \%$ of controls. ${ }^{4}$ In the present series, vascular compression of the nerve was seen in $66 \%$ of patients in whom trigeminal neuralgia was assumed to be due to multiple sclerosis. Whereas response to microvascular decompression remains the ultimate test of the importance of vascular compression, the high incidence of vascular compression in the present study strongly suggests a causal relation rather than a chance association of vascular compression in patients with trigeminal neuralgia associated with multiple sclerosis. The relevance of neurovascular compression in one patient with an undistorted nerve, as well as the importance of vascular compression of the nerve on the side which had been cured by a radiofrequency lesion of the trigeminal root in the patient with bilateral trigeminal neuralgia whose pain on the second side responded only to microvascular decompression, remain unproved.

The pathophysiological processes underlying trigeminal neuralgia remain an enigma. ${ }^{17-20}$ It is known that compression, distortion, or stretching of the trigeminal nerve by a slow growing tumour, aberrant vessels, or vascular malformations, can cause typical trigeminal neuralgia. Intrinsic brain lesions such as syringobulbia, brain stem infarcts and, most commonly multiple sclerosis, may also cause trigeminal neuralgia. The most plausible hypothesis regarding pathophysiology, which explains the fact that both extrinsic and intrinsic brain lesions may produce typical trigeminal neuralgia as well as the paroxysmal nature of the pain, is that trigeminal neuralgia had a peripheral cause and a central pathogenesis. Fromm et al have postulated that chronic irritation of the peripheral nerve leads both to ectopic action potentials within the nerve and failure of segmental inhibition in the trigeminal nucleus. ${ }^{17}$ This theory explains the origin of pain in the case of tumours and aberrant vessels compressing the nerve, when ectopic action potentials generated in the nerve would presumably be responsible, and also the cause of pain in patients with intrinsic brain lesions such as multiple sclerosis when a plaque would lead to increased activity within the trigeminal nucleus. Regardless of which of 
Table 1 Summary of clinical history, MRI, and treatment outcome of seven consecutive patients with trigeminal neuralgia and multiple sclerosis

\begin{tabular}{|c|c|c|c|c|c|c|}
\hline $\begin{array}{l}\text { Patient } \\
\text { No }\end{array}$ & $\begin{array}{l}\text { Duration } \\
\text { of multiple } \\
\text { sclerosis }\end{array}$ & Age & $\begin{array}{l}\text { Side and } \\
\text { division }(s)\end{array}$ & Pathology & Treatment & Outcome \\
\hline $\begin{array}{l}1 \\
2 \\
3 \\
4\end{array}$ & $\begin{array}{r}5 \\
12 \\
25 \\
20\end{array}$ & $\begin{array}{l}40 \\
54 \\
54 \\
60\end{array}$ & $\begin{array}{l}\text { Right 1-3 } \\
\text { Left 2 } \\
\text { Left 3 } \\
\text { Left 2-3 }\end{array}$ & $\begin{array}{l}\text { Vessel } \\
\text { Plaque } \\
\text { Vessel } \\
\text { Epidermoid } \\
\text { tumour }\end{array}$ & $\begin{array}{l}\text { MVD } \\
\text { CBZ } \\
\text { Alcohol } \\
\text { Acupuncture, } \\
\text { awaiting }\end{array}$ & $\begin{array}{l}\text { Pain free } \\
\text { Partial control } \\
\text { Pain free } \\
\text { Partial control }\end{array}$ \\
\hline 5 & 36 & 71 & $\begin{array}{l}\text { Bilateral, } \\
\text { Left } 1 \\
\text { Right } 2\end{array}$ & $\begin{array}{l}\text { Two vessels } \\
\text { Right side, } \\
\text { single vessel left side }\end{array}$ & $\begin{array}{l}\text { surgery } \\
\text { MVD right side } \\
\text { RFL left side }\end{array}$ & $\begin{array}{l}\text { Pain free } \\
\text { Died }\end{array}$ \\
\hline 6 & 25 & 44 & $\begin{array}{l}\text { Bilateral, } \\
\text { Right V3, } \\
\text { Left V3 }\end{array}$ & Vessel & Alcohol & Pain free \\
\hline 7 & 20 & 40 & $\begin{array}{l}\text { Left, } \\
1 \text { and } 2\end{array}$ & Two vessels & Nerve block & Pain free \\
\hline
\end{tabular}

$M V D=$ microvascular decompression $; C B Z$ = carbamezepine; $R F L=$ radiofrequency lesion.

these mechanisms operates, episodic activation of the trigeminal neurons may result in paroxysms of pain whenever these bursts of activity exceed the threshold for activation of pain neurons in the trigeminothalamic tract. To satisfactorily explain the unexpectedly high incidence of vascular compression of the nerve in patients with trigeminal neuralgia and multiple sclerosis, we wish to extend this theory further. Given the occurrence of trigeminal neuralgia in about $1-2 \%$ of patients with multiple sclerosis, and that trigeminal neuralgia is encountered in only $0.01 \%$ of the general population in whom an $8 \%$ incidence of vascular contact with the nerve is expected, we postulate that vascular compression is more likely to cause trigeminal neuralgia in patients with multiple sclerosis than it is in the population without this condition, because of underlying hyperexcitability in the trigeminal nucleus. This same argument may explain the higher incidence of bilateral occurrence of trigeminal neuralgia in patients with multiple sclerosis, and perhaps also the earlier onset. It also satisfactorily explains the cause of symptoms in a patient we have recently encountered with bilateral trigeminal neuralgia associated with CharcotMarie-Tooth syndrome, in whom bilateral microvascular decompression cured the trigeminal neuralgia on both sides after failure of all other treatments. In such cases an

Table 2 Outcomes of four procedures for the treatment of trigeminal neuralgia

\begin{tabular}{|c|c|c|c|}
\hline Procedure & Outcome & Duration of action & Sensory/motor loss \\
\hline Glycerol injection & $85 \%$ effective & $\begin{array}{l}\text { Short } \\
\text { About } 6 \text { months }\end{array}$ & $\begin{array}{l}\text { Slight sensory loss } \\
\text { Corneal anaesthesia possible } \\
\text { Masseter weakness rare }\end{array}$ \\
\hline Alcohol injection & $85 \%$ effective & $\begin{array}{l}\text { Variable, may be } \\
\text { long }\end{array}$ & $\begin{array}{l}\text { Sensory loss } \\
\text { Other cranial nerve loss } \\
\text { Corneal anaesthesia }\end{array}$ \\
\hline $\begin{array}{l}\text { Radiofrequency } \\
\text { lesion }\end{array}$ & $90 \%$ effective & $\begin{array}{l}\text { Long } \\
25 \% \text { relapse rate }\end{array}$ & $\begin{array}{l}\text { Frequent sensory loss } \\
\text { Corneal anaesthesia if } \mathrm{V}_{1} \\
\text { Masseter weakness } \\
\text { occasionally }\end{array}$ \\
\hline $\begin{array}{l}\text { Microvascular } \\
\text { decompression }\end{array}$ & $90 \%$ effective & Long & $\begin{array}{l}3 \% \text { morbidity (damage to } \\
\text { other cranial nerves) } \\
1 \% \text { mortality }\end{array}$ \\
\hline
\end{tabular}

intrinsic neurological abnormality is assumed to form the basis for the provocation of trigeminal neuralgia by neurovascular compression.

Jannetta ${ }^{2}$ has suggested that the pain of trigeminal neuralgia in patients with multiple sclerosis is milder than that seen in the idiopathic group. All the patients in the present study had severe symptoms unresponsive to drug treatment and had been referred to a pain institute with a special interest in trigeminal neuralgia; therefore we cannot conclude that our cohort is representative of the overall population of patients with multiple sclerosis and trigeminal neuralgia, and we eagerly await validation of our results by others.

The fact that most patients with trigeminal neuralgia respond to drug treatment and percutaneous procedures on the ganglion, presumably even those with vascular compression, highlights the fact that cure of pain can be effected by interruption of the pain pathway at one of many sites. ${ }^{21-24}$ As eventually there is a poor response to both drug treatment and percutaneous ablative procedures in patients with trigeminal neuralgia and multiple sclerosis, as is the case to a lesser extent in trigeminal neuralgia in general, it is important to identify vascular compression to effect appropriate treatment.

The discovery of trigeminal nerve compression by an epidermoid tumour was almost certainly a chance finding. In a patient with a condition such as multiple sclerosis which may cause neurological deficit, a search for a coexistent potentially curable cause of the same clinical manifestation is unlikely to be carried out. ${ }^{21-24}$ The same is true of idiopathic trigeminal neuralgia. In a large recent study the $10 \%$ of cases secondary to tumours were discovered only after an average delay of 6.3 years. ${ }^{9}$ All patients with trigeminal neuralgia have been equally disadvantaged in the past by the inability to demonstrate vascular compression of the nerve without recourse to exploratory surgery. In addition, patients with multiple sclerosis are further disadvantaged by a disease process which might have explained their symptoms irrespective of a coexistent 
cause such as tumour or vascular compression.

Despite advances in both MRI and laboratory technology, the diagnosis of multiple sclerosis remains a clinical one, and most clinicians should remain extremely reluctant to forward a diagnosis of multiple sclerosis without firm clinical evidence. ${ }^{1125}$ Poser et al have developed criteria to aid the clinician in coming to the correct diagnosis. ${ }^{26}$ The presence of abnormalities referable to multiple lesions within the CNS, separated both in time and space, with evidence of remissions, strongly favours a diagnosis of multiple sclerosis. In a patient with one CNS abnormality and coexistent trigeminal neuralgia, it seems reasonable to attribute both to the same underlying pathological process. Although we suspect that trigeminal neuralgia is simply more likely to develop in patients with multiple sclerosis and vascular compression of the nerve, this remains unproved; we emphasise that trigeminal neuralgia can only be used as corroborative evidence to support a diagnosis of multiple sclerosis if secondary causes such as vascular compressions and tumours have first been excluded.

\section{Conclusion}

Advances in MRI may allow demonstration of the cause of symptoms in most patients with trigeminal neuralgia. Failure to investigate fully the cause of pain in each individual case of trigeminal neuralgia associated with multiple sclerosis may deprive an already disabled patient of a potential surgical cure.

1 Dandy WE. Concerning the cause of trigeminal neuralgia. Am f Surg 1934;19:947-58.

2 Jannetta PJ. Neurovascular compression in cranial nerve and systemic disease. Ann Surg 1980;192:518-25.

3 Fromm GH, Terrence CF, Maroon JC. Trigeminal neuralgia. Current concepts regarding etiology and pathogenesis. Arch Neurol 1984;41:1204-7.

4 Meaney JFM, Miles JB, Nixon TE, Whitehouse GH, Ballentyne ES, Eldridge PR. Vascular contact with the fifth cranial nerve at the pons in patients with trigeminal neuralgia: detection with $3 D$ FISP imaging. $A \mathscr{F} R A m$ f Roentgenol 1994;163:1447-52.
5 Harris W. Rare forms of paroxysmal trigeminal neuralgia and their relation to disseminated sclerosis. $B M F$ 1950; 2:1015-9.

6 Chakravorty BG. Association of trigeminal neuralgia with multiple sclerosis. Arch Neurol 1966;14:95-9.

7 Olafson RA, Rushton JG, Sayre GP. Trigeminal neuralgia in a patient with multiple sclerosis. $\mathcal{F}$ Neurosurg 1966;24: 755-9.

8 Brisman R. Trigeminal neuralgia and multiple sclerosis. Arch Neurol 1987;44:379-81.

9 Cheng TMW, Cascino TL, Onofrio BM. Comprehensive study of diagnosis and treatment of trigeminal neuralgia study of diagnosis and treatment of trigeminal neuralgia

10 Adler CH, Zimmerman RA, Savino PJ, Bernardi B, Bosley TM, Sergoti RC. Hemifacial spasm: evaluation by magnetic resonance tomographic angiography. Ann Neurol 1992;32:502-6.

11 Wallace CJ, Seland TP, Fong TC. Multiple sclerosis: the impact of MR imaging. AfR Am $\mathcal{f}$ Roentgenol 1992;158: 849-57.

12 Pollack IF, Jannetta PJ, Bissonette DJ. Bilateral trigeminal neuralgia: a 14-year experience with microvascular decompression. $₹$ Neurosurg 1988;68:559-65.

13 Lazar ML, Kirkpatrick JB. Trigeminal neuralgia and multiple sclerosis: demonstration of the plaque in an operative case. Neurosurgery 1979;5:711-7.

14 Kerr FWL. Correlated light and electron microscopic observations on the normal trigeminal ganglion and sensory root in man. $\mathcal{F}$ Neurosurg 1967;26:168-72.

15 Ballantyne ES, Page R, Meaney JFM, Miles JB. Co-existent trigeminal neuralgia, hemifacial spasm and hypertension: pre-operative imaging of neurovascular compression. $\mathcal{F}$ Neurosurg 1994;80:559-63.

16 Furuya Y, Ryu H, Uemura K, et al. MRI of intracranial neurovascular compression. $\mathcal{f}$ Comput Assist Tomogr 1992;16:503-5.

17 Fromm GH, Terrence CF, Chattha AS. Role of inhibitory mechanisms in trigeminal neuralgia. Neurology 1981; 31:683-7.

18 Kugerberg $\mathrm{E}$, Lindblom $\mathrm{U}$. The mechanism of the pain in trigeminal neuralgia. $f$ Neurol Neurosurg Psychiatry 1959;22:36-43.

19 Burchiel KJ. Abnormal impulse generation in focally denervated trigeminal roots. $f$ Neurosurg 1980;53: 674-83.

20 Calvin WH, Loeser JD, Howe JF. A neurophysiological theory for the pain mechanism of tic douloureux. Pain 1977;3:147-54.

21 Brett DC, Ferguson GG, Ebers GC, Patty DW. Percutaneous trigeminal rhizotomy. Treatment of trigeminal neuralgia secondary to multiple sclerosis. Arch Neurol 1982;39:219-21.

22 Linderoth B, Håkanson S. Paroxysmal facial pain in disseminated sclerosis treated by retrogasserian glycerol injection. Acta Neurol Scand 1989;80:341-6.

23 Dieckman G, Veras G, Sogabe K. Retrogasserian glycerol injection or percutaneous stimulation in the treatment of typical and atypical trigeminal pain. Neurol Res 1987; typical

24 Fromm GH. Medical treatment of patients with trigeminal neuralgia. In: Fromm GH, Sessle BJ, eds. Trigeminal neuralgia. Stoneham MA: Butterworth, 1991: 131-44.

25 Fazekas F, Offenbacher H, Fuchs S, et al. Criteria for an increased sensitivity of MRI interpretation in elderly subjects with suspected multiple sclerosis. Neurology 1988;38:1822-5.

26 Poser CM, Paty DW, Scheinberg L, et al. New diagnostic criteria for multiple sclerosis: guidelines for research protocols. Ann Neurol 1983;13:227-31. 